\title{
An Anatomy of Dutch Question Intonation
}

\author{
Judith Haan, Vincent J. van Heuven, Jos J.A. Pacilly en Renée van Bezooijen
}

\section{Introduction}

0.1. Aim of this research. In recent years, the formal elements of Dutch intonation have been laid down in two comprehensive models ('t Hart, Collier and Cohen 1990, Gussenhoven and Rietveld 1992). With these two formal models at our disposal, the stage seems set for further explorations, notably of the relationship between form and function. The present study focused on acoustic correlates of a major functional contrast; viz. the contrast between declarativity and interrogativity, two functions featuring prominently in everyday communication. Generally speaking, declarative utterances are used for making announcements, relating events, stating conclusions and so on. By contrast, interrogative utterances make a direct appeal to a listener for a reply. While declarative utterances usually have the most basic form of clause available in a language, interrogativity may be marked by special syntactic and/or lexical means, in particular by inversion of subject and finite verb or by the presence of a question word. These, however, are by no means the sole indicators of the contrast between declarativity and interrogativity. It is assumed that intonation, also, plays an important role, notably in interrogative utterances lacking the lexico/syntactic devices of interrogativity ('declarative questions'). Thus, if Dutch interrogativity has intonational characteristics of its own, it seems plausible for such characteristics to be stronger as lexico/ syntactic marking for interrogativity is weaker.

For the purpose of our research, declarativity and interrogativity are seen as forming a continuum, with statements (S) at one extreme end, and declarative questions (D) at the other; in between are the wh-questions (W, marked both by question word and inversion) and yes/no questions ( $\mathrm{Y}$, marked by inversion only). Our objectives were (i) to determine to what extent the acoustic properties of interrogativity. are different from those of declarativity, and (ii) to pinpoint possible acoustic differences among the question types themselves. Also, we wished to ascertain to what extent such acoustic characteristics still need to be incorporated into the two formal models of Dutch intonation mentioned above.

0.2. Question intonation across languages. Crosslinguistically, question intonation has always been strongly associated with a local terminal rise in pitch. In a medieval text from Münster, monks were instructed in Latin to raise their pitch at question marks when reciting the written texts of liturgical prayers (cf. Hadding-Koch 1961). 
Today, in part of the literature question intonation is still largely identified with this final rise (e.g. Lieberman 1967, Brown, Currie and Kenworthy 1980, Cooper and Sorensen 1981, Eady and Cooper 1986).

It cannot be doubted that the final rise serves as an important diagnostic for identifying utterances as questions; yet, it occurs very late in the utterance. Asking a question is tantamount to eliciting a verbal response from a listener and it seems important for the latter to be made aware of this 'obligation' as early as possible. Therefore, we would expect questions to also contain pitch cues well before the final rise. If, for instance, pitch in questions is high right from the start, the listener could start processing the utterance as a question straightaway. The occurrence of such (early) cues has, in fact, been reported. In a large-scale survey of question intonation in 177 languages from all over the world, Hermann (1942) claims that interrogativity is always signalled by high pitch somewhere in the utterance. This high pitch may manifest itself both locally, e.g. in the initial, medial or final portion of the utterance (cf. Hadding-Koch and Studdert-Kennedy 1964), and globally, either in the guise of a raised register ${ }^{1}$ (cf. Bolinger 1982, Lindsey 1985, Geluykens 1986, Inkelas and Leben 1990) or of the absence of F0 downtrend; presence of F0 downtrend is commonly observed in and across statements (Thorsen 1980, Vaissière 1983, Inkelas and Leben 1990).

0.3. Dutch question intonation. As far as Dutch question intonation is concerned, there are early claims in the literature that the Dutch question contour is hammockshaped, i.e., it has a high beginning, a low stretch in between and an equally high ending (van Es 1932, Daan 1938). It has also been claimed that Dutch questions are realized in a higher register (van Alphen 1914, van Es 1932). So far, however, no experiments have been carried out to test such claims. In the two formal accounts of Dutch intonation mentioned above the function interrogativity is not explicitly dealt with; however, both models feature formal units which may serve as a final interrogative rise. That the element of high(er) pitch in Dutch questions is perceptually relevant was demonstrated by Gooskens and van Heuven (1995). Their results indicate that Dutch listeners, when deciding whether an otherwise ambiguous utterance is a statement or a question, favour questions from which the canonical F0 downtrend has been removed.

0.4. Hypotheses. Taking the above theoretical claims into account, we formulated the hypothesis that, in comparison with Dutch statements, Dutch questions are characterized by higher pitch in at least the following ways. First, questions will

Register is defined as an area within a given speaker's overall pitch range, enclosed by the highest and lowest frequency within which tones of a particular utterance are realized (cf. Clements 1990). 
have final rises Second, they will be generally realızed on a higher register Third, they will show less global downtrend of FO or even an upward trend Finally, these pitch properties will be strongest in declarative questions, which lack any lexical or syntactic marking for interrogativity, weakest in wh-questions, which are both lexically and syntactically marked, and intermediate in yes/no questions with only syntactıc marking for interrogativity, the hypothesized order of pitch height will be referred to as $\mathrm{D}>\mathrm{Y}>\mathrm{W}>\mathrm{S}$

\section{Method}

11 Materials The design was based on two declaratıve sentences (differing in lexical material only), each with two accentable syllables containing identical vowels In their basic forms, these utterances served both as statements (Renée has some meat left and Marina wants to sell her mandolin) and as declarative questions (Renée has some meat left ${ }^{7}$ and Marma wants to sell her mandolin ${ }^{2}{ }^{2}$ With minimal changes they were transformed into yes/no questions (e g Has Renée any meat left?) and wh-questions (e g What (sort of) meat has Renée left ${ }^{\text {? }}$ ) These four target versions of the two basic sentences occurred both in isolation, and as first or second members of minımal paragraphs (1 e, sentence parrs such as Has Renée any meat left? The cat still needs to be fed) Thus, each target sentence could either be followed or preceded by a context sentence, which in turn could be either a statement or a yes/no question The eight isolated sentences and 32 sentence pairs were sem1randomized (no immediate successions of derivations of the same basic sentence were allowed), and printed on 40 separate cards

12 Speakers and recording procedures Subjects were ten native speakers of Standard Dutch between 20 and 48 years of age (five men, five women) They read out the entire set of sentences twice, half of them in reverse order so as to balance possible order effects Subjects, who were not aware of the goals of the experiment, were instructed to read out the material in an uninhibited way, makıng sure they took notice of question marks, if present When a speaker made an error, s/he was requested to repeat the utterance (parr) As regards accentuation, no explicit instructions were given Recordings were made on digital audio tape (48 $1 \mathrm{kHz}, 16$ bits) in a soundproofed studio, and resulted in a corpus of 800 target utterances The full design of the corpus is exemplitied in appendix 2

2 Here the English sentences have been transhiterated from Dutch Appendix 1 hsts the full set of ortginal sentences and sentence pairs in Dutch (plus phonetic transcription) 
1.3. Measurements. Fundamental frequency (F0) was extracted from the recordings by the method of subharmonic summation (Hermes 1988). We determined raw parameters, i.e. F0 values measured at specific points in time, as well as regression parameters, i.e. global values and slopes of F0 computed across the entire utterance. The raw parameters included F0 onset (first reliable F0 value at sentence onset), F0 maximum (highest $\mathrm{F} 0$ value attained anywhere in the utterance, excluding the final rise), F0 minimum (lowest reliable F0 value in utterance), and F0 offset. This latter value was measured twice, that is, once as the last F0 value including the final rise (if present), and once as the last F0 value discounting a final rise. The onsets of the final rises were determined by visual inspection (as well as by ear) and defined as the latest (rightmost) FO minimum before the end of the utterance.

Global trends in F0 were described by means of the intercepts and slope coefficients of regression lines, which can be determined automatically. Regression techniques were preferred over the so-called visual abstraction method that has usually been applied to this type of data (i.e., the fitting of bottom and top declination lines to a raw F0 curve by eye). Our reasons for abandoning the visual abstraction method were twofold. First, visual abstraction is subjective and rather difficult to reproduce (cf. Lieberman 1985). Second, the visual abstraction method would be too time--consuming when applied to a dataset as large as ours.'

The automatic determination of the global parameters proceeded as follows:

(i) An all-points linear regression line was calculated for $\mathrm{F} 0$ as a function of time.

(ii) A lower trend line was calculated for only those F0 points located below the all-points regression line. The lower regression line will capture the essentials of the lower declination trend; slopes will be more or less congruent, the intercept, however, will be closer to the mean.

(iii) An upper trend line was fitted through all F0 points above the all-points regression line. The upper regression line will roughly follow the slope of the high declination but its intercept, again, will be closer to the mean.

It should be noted that all regression lines were fit to the data points minus the terminal rise (if present). The distance between the upper and lower regression lines will roughly capture the middle $50 \%$ of the F0 range and thus allow comparison of height and width of register across utterances. ${ }^{4}$ In sum, differences in slope and register can be adequately studied using regression techniques. Figure 1 gives an overview of both raw and regression parameters.

3 In a later stage of our research the exact relationship between the regression approach and visual abstraction data in part of our earlier materials will be examined in detail.

4 In fact, highly realistic high and low declination lines will be obtained if, the upper and lower regression lines are drawn at twice their mean distance from the all-points regression line. 
F0 values were expressed in ERBs. The psycho-acoustic ERB-scale rates differences in pitch according to perceptully relevant frequency quanta, enabling meaningful comparison of F0-intervals between speakers, both within and between sexes (Hermes and van Gestel 1991, Ladd and Terken 1995).

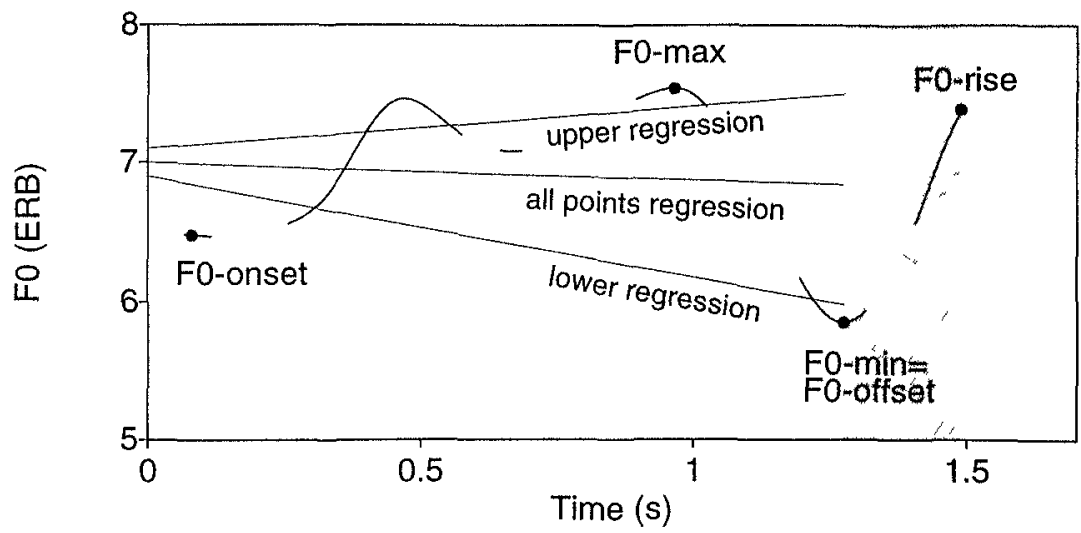

Figure 1. Raw parameters and regression parameters for an isolated utterance.

\section{Results}

The data were subjected to analysis of variance with POSITION (isolated, first, or second in pair), SENTENCE TYPE (S, D, Y, W) and LEXICAL CHOICE (Renée, Marina) as fixed effects, and with SPEAKER nested under SEX as a random effect. ${ }^{5}$ In this article we will concentrate on the linguistic aspects of the research. Two factors in the design have linguistic import, viz. SENTENCE TYPE and POSITION of target sentence within paragraph. The results revealed numerous significant effects for SENTENCE TYPE, our crucial factor here, but not a single significant effect was found for the second linguistic variable: POSITION of the target sentence. For this reason no further results will be reported for POSITION, and the results in the following subparagraphs will be based on simplified analyses of variance, in which sentence type will be the only (fixed) factor. It should be noted that speaker and especially sex also exert significant effects; due to space limitations these will not be reported in the present article.

The SPSS design statement for the ANOVA was generated by the utılity MANOVET (Multiple ANalysis Of Varıance Error Terms) written by Hugo Quené of Utrecht University 
We will first present the effects of SENTENCE TYPE on properties of the final rise, the canonical question marker ( $\S 2.1$ ). Next we will look at the effects of SENTENCE TYPE on the four criterial local pitch measures, viz. the earliest and latest, as well as the highest and lowest pitches found in each target utterance $(\S 2.2)$. The effects on the global indicators of downtrend and register size will be presented last $(\S 2.3)$.

2.1. Final rises. None of the 200 statements ended in a final rise. As a category, the 600 questions distinguished themselves by a massive occurrence of final rises, in the predicted order: declarative questions $99 \%$, yes/no questions $95 \%$ and wh-questions $67 \%$. The latter percentage is not unexpected, as it has been suggested in the literature on other Germanic languages that this question type often lacks a final rise, (e.g. in English and German, cf. Pierrehumbert and Hirschberg 1990).

Figure 2 presents the means for two acoustic parameters that were determined for only those question utterances that were produced with a final rise: the terminal frequency (upper line) and the onset frequency (lower line) of the final pitch rise; the excursion size of the rise is implicit in the distance between the upper and lower frequencies. The effect of QUESTION TYPE is highly significant for onsets of the final rises, $F(2,518)=18.3(p<0.001)$, as well as for the end points $F(2,518)=4.7$ $(\mathrm{p}<<0.001)$. Both onset and terminal frequencies are highest for declarative questions, intermediate for yes/no questions and lowest for wh-questions; the onset frequencies are significantly different for each of the three question types, the terminal frequencies are sigificantly different only for the contrast between whquestions and declarative questions (Newman-Keuls procedure with $\alpha=0.05$ ). The excursion size of the final rise does not differ significantly for the three question types, $\mathrm{F}(2,518)=3.0$ (ins.).

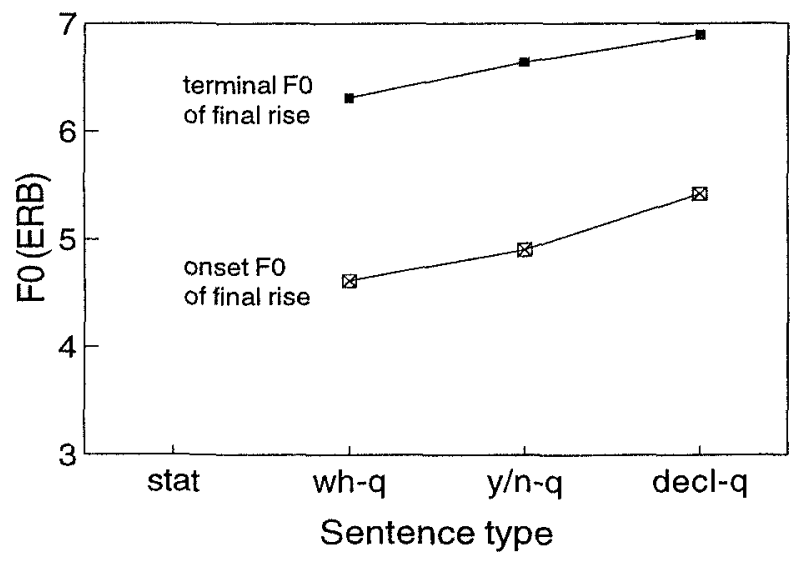

Figure 2. Onset and terminal FO (ERB) of final rise broken down bij sentence type. Utterances without a final rise were excluded from the analysis. 
2.2. Raw parameters of register. Figure 3 presents the mean values of the raw F0parameters indicative of mean pitch and register width, broken down by the four sentence types (i.e., statements and three types of question). The data were subjected to oneway analyses of variance as in $\S 2.1$, but with a four-level SENTENCE TYPE factor (this time including statement).

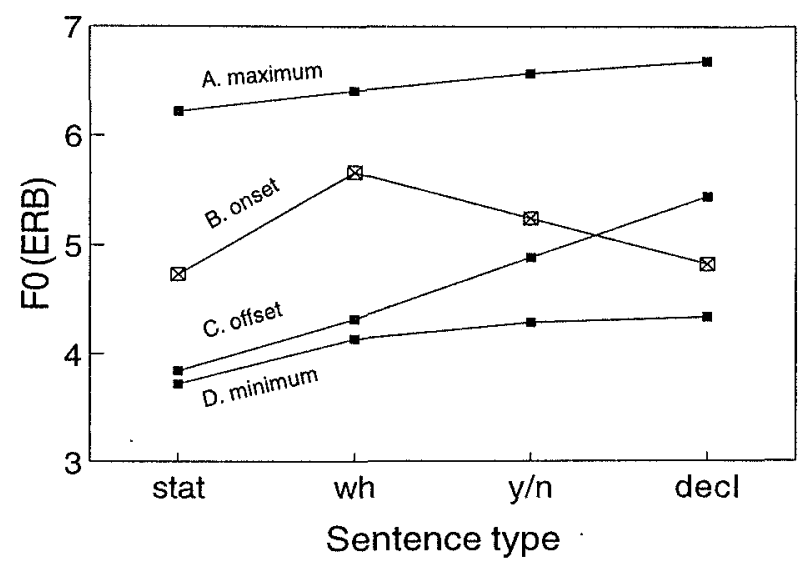

Figure 3. Mean FO (in ERB) at FO-maximum (line A, discounting the final rise), sentence onset (line $B$ ), sentence offset (line $C$, last measurement before onset of final rise), and at $F 0$ minimum (line $D$ ).

The lowest pitch ever attained during the utterance (line $D$ ) is lowest for statements, and monotonously increases in the predicted order $S<W<Y<D, F(3,752)=52.4$ $(\mathrm{p}<<0.001)$; all types differ significantly by the Newman-Keuls procedure. The highest pitch in the utterance (line A) shows the same effect, $F(3,796)=26.6$ $(\mathrm{p}<<0.001)$; the difference between $\mathrm{Y}$ and $\mathrm{D}$ is not significant, however. By far the strongest effect was obtained for the final pitch reached before the beginning of the final rise (if present), $F(3,796)=149.7$ ( $p<<0.001$ ). Again, the means for the four sentence types differ in the predicted order and all contrasts are significant.

There is one local F0-measure that does not conform to the predicted order $\mathrm{S}<\mathrm{W}<\mathrm{Y}<\mathrm{D}$, viz. the pitch at the onset of the sentence. Low onset pitches are found for statements and declarative questions, whereas higher onsets characterize whquestions and $y / n$-questions. The effect is highly significant, $F(3,796)=144.0$ $(p<0.001)$; all differences are siginificant by the Newman-Keuls procedure, except 
the contrast between statement and declarative. We will return to this apparent deviation from the overall - and predicted - pattern later.

2.3. Global parameters of downtrend and register width. Figure 4 summarises the means of the global parameters for downtrend and (implicitly) register width. For each of the four sentence types, the onset (intercept) and terminal frequency (both in ERB) of the upper and lower regression lines have been plotted in separate panels. The slopes of the regression lines have been specified in ERB/s; here a negative slope coefficient indicates downtrend of F0 (declination), a positive coefficient stands for uptrend (inclination). To facilitate the quantification of register width, the distance in the ERB-domain has been indicated at the temporal midpoint of the utterances (i.e. at the $50 \%$ point along the normalised time axis). For realistic estimates of register width, this distance should be doubled (see also footnote 4).
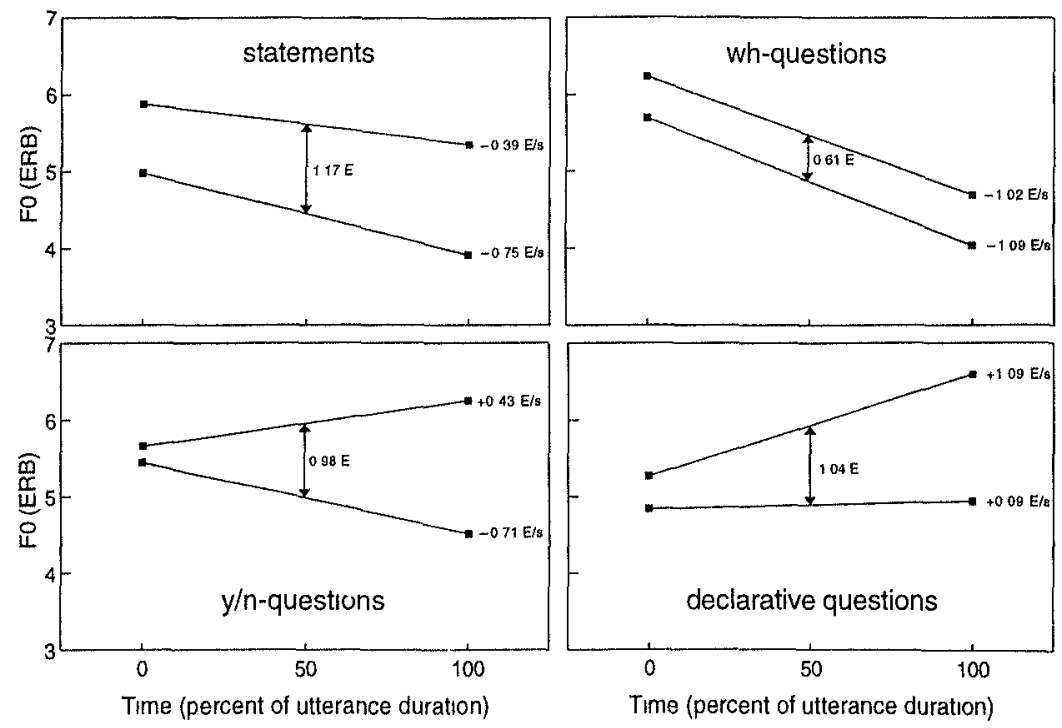

Figure 4. Onset and terminal frequencies (in ERB) of upper and lower regression lines and their respective slope coefficients (in ERB/s) for four sentence types; vertical arrows indicate mean register width at the temporal midpoint.

The lower regression line is less negative in the order $\mathrm{W}<\mathrm{S}<\mathrm{Y}$ and even positive for $D, F(3,796)=82.9$ ( $p<<0.001)$; only the contrast between $S$ and $Y$ is not significant. The same effect, but larger, is found in the upper regression line, with 
inclination for $\mathrm{Y}$ and $\mathrm{D}, \mathrm{F}(3,796)=159,2(\mathrm{p}<<0.001)$; here all sentence types are significantly different from each other in the order $\mathrm{W}<\mathrm{S}<\mathrm{Y}<\mathrm{D}$.

SENTENCE TYPE exerts a significant effect on the register width at the temporal midpoints, $F(3,796)=89.8$ ( $p<<0.001$ ). The post hoc analysis for contrasts reveals that the register width of statements, yes/no-questions and declarative questions do not differ from each other. Wh-questions, however, have a substantially (roughly $50 \%$ ) narrower register than the other sentence types.

\section{Conclusions and discussion}

The first conclusion of this experiment is that the functional contrast between Dutch declarativity and interrogativity has clear acoustic correlates which can be captured in terms of, respectively, low pitch versus high pitch. Not only does the majority of questions end in a steep rise of F0, questions are also unlike statements in that they are realized in a higher register of the speaker's overall pitch range. Besides, in two out of the three question types the overall downward trend of F0, characteristic of declarative speech, is replaced by an upward trend. Such local and global differences in pitch height between statements and questions have been frequently demonstrated for other, often unrelated languages. Thus, our findings provide fresh evidence for the general claim that greater pitch height in questions can be regarded a (near) universal of language (cf. Hermann 1942, Lindsey 1985).

At the same time, however, it has turned out to be hazardous to lump the three question types together to form one single category of Dutch Question Intonation. If the different question types share important pitch level properties, the experiment has also made it clear that each separate question type has a characteristic pitch profile of its own which may depart from the categorical average. Thus, while the declarative question ranks highest with respect to final frequency (both with and without the final rise), to local minima and maxima, as well as to the upward global F0 trend, its onset is unexpectedly low, in fact not much higher than that of statements. By contrast, while the wh-question starts from quite a high onset, it altogether lacks an upward F0 trend; indeed, its downtrend is steeper than that in statements. At the same time, register in wh-questions is only half as wide as in statements; if in the other question types register is certainly narrower than in statements, the differences are less striking. In all respects, the yes/no question holds an intermediate position between the wh-question and the declarative question. Looking at these results, it might be concluded that a high onset does not act as an important early cue for interrogativity. Thus, when deciding whether an otherwise ambiguous utterance is a statement or a question listeners may be guided by the combination of two other early cues, i.e., the strongly raised register and the early upward F0 trend so characteristic of the declarative question. Alternatively, the finding that in declarative questions the high offset goes together with a low onset whereas in statements it is 
exactly the other way round (cf $\mathrm{B}$ and $\mathrm{C}$ in figure 3 ) might suggest a maximalized intonational contrast between the two, making up for the absence of lexico-syntactic cues

It should be pointed out, by the way, that the high(er) pitch found in questions may, in part, have phonological causes as well It was observed in a pilot experiment that questions often involved a falling initial pitch accent rather than the rising one customary in statements Thorough examination of the 800 contours of the present experiment will have to shed more light on this matter in some later stage of the research

In the introduction, we also expressed interest in the division of labour between intonational and lexico-syntactic cues within the continuum statement-declarative question Having found that pitch is generally higher in questions than in statements (discounting the final rise), it could also be observed that, among the questions, the various pitch level properties generally manifested themselves in the hypothesized order $\mathrm{D}>\mathrm{Y}>\mathrm{W}$ This indicates the existence of an inverse proportionality, in the sense that intonational marking of questions is generally stronger to the extent that lexical and/or syntactic marking are weaker or altogether absent

Insight into the different pitch characteristics of statements and questions may prove beneficial to speech technology In German, for instance, rule-generated questions were judged to sound far less natural and adequate than statements (Mobius 1993) As to Dutch speech technology, whether based on the framework of the IPO model ('t Hart, Collier and Cohen 1990) or on autosegmental models (Gussenhoven and Rietveld, 1995), this has so far been mainly concerned with statements If quest1ons have been artificially generated, it was primarily the final rise in FO that had to make them acoustically distinct from statements However, when questions are shown to need at least a higher register and when the three different question types can be seen to vary substantially as far as their phonetics of downtrend, onset level, register width and final rise are concerned, it may be possible for artificial questions to sound more natural.

\section{References}

Alphen, J van (1914) 'De Vraagzin', De Nteuwe Taalgıds 8, 88-95

Bolınger, D (1982) 'Nondeclaratıves from an Intonational Standpoint', in R Schneider, K Turte, and R Chametzky, eds, Papers from the Parasession on nondeclaratives Chicago Linguistic Society, Chicago

Brown, G , K Curne and J Kenworthy (1980) Questtons of Intonatton, Croom Helm, London

Clements, G N (1990) 'The Status of Register in Intonation Theory Comments on the Papers by Ladd and by Inkelas and Leben', in J Kingston and M Beckman, eds, Papers in Laboratory Phonology I, Cambridge University Press, Cambridge, 58-71

Cooper, W E and J M Sorensen (1981) Fundamental Frequency in Sentence Production Springer Verlag, New York

Daan, J (1938) 'Dialect and Pitch-Pattern of the Sentence', Proceedings 3rd International Congress of Phonetic Sciences, 473-481 
Eady, S J and W E Cooper (1986) 'Speech Intonation and Focus Location in Matched Statements and Questions', Journal of the Acoustic Society of America 80, 402-415

Es, G A van (1932) 'Syntaxis en Dialectstudie IV, Intonatıe en Syntaxıs', Onze Taaltuin 122-128

Gelu1jkens, R (1986) Questioning Intonatıon, Antwerp Papers in Lingurstics 48

Gooskens, C and V J van Heuven (1995) 'Declination in Dutch and Danısh Global Versus Local Pitch Movements in the Perceptual Characterisation of Sentence Types', Proceedings 13th International Congress of Phonetic Sciences 2, 374-377

Gussenhoven, C and T Rietveld (1992) 'A Target-Interpolation Model for the Intonation of Dutch', Proceedings of the Second International Conference on Spoken Language Processing 2, 1235-1238

Hadding-Koch, K (1961) Acousttc-Phonettc Studies on the Intonation of Southern Swedish, Travaux de l'Institut de Phonétıque de Lund III, Gleerup, Lund

Hadding-Koch, K and M Studdert-Kennedy (1964) 'An Experimental Study of Some Intonation Contours', Phonetica 11, 175-185

Hart, J 't, R Collier, and A Cohen (1990) A Perceptual Study of Intonation, Cambridge, Cambridge University Press

Hermann, E (1942) Probleme der Frage, Nachrichten Akademie von Wissenschaft, Gottıngen

Hermes, D J (1988) 'Measurement of Pitch by Subharmonic Summation', Journal of the Acoustical Soctety of Amertca 83, 257-264

Hermes, D and J C van Gestel (1991) 'The Frequency Scale of Speech Intonation', Journal of the Acoustical Society of America 90, 97-102

Inkelas, S and W Leben (1990) 'Where Phonology and Phonetucs Intersect the Case of Hausa Intonation', in J Kingston and M Beckman, eds, Papers in Laboratory Phonology I, Cambridge University Press, Cambridge, 35-57

Ladd, D R and J M B Terken (1995) 'Modelling Intra- and Inter-speaker Pitch Range Varration', Proceedings 13th International Congress of Phonetic Sctences 2, 386.389

Lieberman, p (1967) Intonation, Perception and Language, MIT Press, CambridgMassachusetts

Lieberman, P, W Katz, A Jongman, R Zımmerman, and M Miller (1985) 'Measures of the Sentence Intonation of Read and Spontaneous Speech in American English', Journal of the Acoustical Society of America 77, 649-659

Lindsey, G A (1985) Intonation and Interrogation Tonal Structure and the Expression of a Pragmattc Function in English and Other Languages, PhD dissertation, University of Californmia, Los Angeles

Mobius, B (1993), 'Perceptual Evaluation of Rule-Generated Intonation Contours for German Interrogatives', in D House and P Touat, eds, Proceedings of an ESCA Prosody Workshop on Prosody, Working papers, Department of Linguistics, Lund University, 41, 216-219

Pierrehumbert, J and J Hirschberg (1990) 'The Meaning of Intonational Contours in the Interpretation of Discourse', in P R Cohen, J Morgan and M E Pollack, eds, Intentions in Communtcation, MIT Press, Cambridge, Massachusetts

Thorsen, N (1980) 'A Study of the Perception of Sentence Intonation - Evidence from Danısh', Journal of the Acoustical Soctety of Amertca 67, 1014-1030

Vatssıère, J (1983) 'Language-Independent Prosodıc Features', in A Cutler and D R Ladd, eds, Prosody Models and Measurements, Springer Verlag, Berlın 
Appendix 1: Overview of stimulus sentences

\begin{tabular}{|c|c|c|c|}
\hline Type & Target sentence & Type & Context sentence \\
\hline $\begin{array}{l}\text { Stat } \\
\mathrm{Y} / \mathrm{N} \\
\mathrm{Wh}\end{array}$ & $\begin{array}{l}\text { Renée heeft nog vlees over } \\
\text { /rəne: he:ft nox fle:s o:vər' } \\
\text { Heeft Renée nog wat vlees over? } \\
\text { /he:ft rəne: nox vat fle:s o:vər/ } \\
\text { Wat heeft Renée nog voor vlees over? } \\
\text { Nat he:ft rəne: nox fo:r vle:s o:vər/ } \\
\text { Renée heeft nog vlees over? } \\
\text { /rone: he:ft nox fle:s o:ver/ }\end{array}$ & $\begin{array}{l}\text { Stat } \\
\text { Y/N }\end{array}$ & $\begin{array}{l}\text { Onze poes moet wat eten hebben. } \\
\text { /Onze pu"s mu't vat e:te hebe/ } \\
\text { Wil de poes nog wat eten hebben? } \\
\text { /UIl de pu's nox vat e:te hebe/ }\end{array}$ \\
\hline $\mathrm{Y} / \mathrm{N}$ & 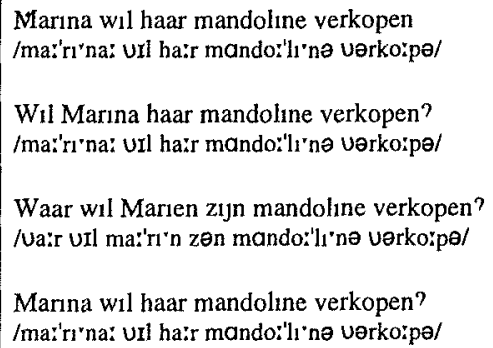 & $\begin{array}{l}\text { Stat } \\
\mathrm{Y} / \mathrm{N}\end{array}$ & $\begin{array}{l}\text { Er is donderdag weer een rommelmarkt } \\
\text { /Er IZ 'donderdax ve:r en 'romelmarkt/ } \\
\text { Is er donderdag weer een rommelmarkt? } \\
\text { /rz ar 'donderdax ve:r en 'romelmarkt }\end{array}$ \\
\hline
\end{tabular}

Appendix 2. Schematic representation of the design. Each cell frequency must be multplied by 4 (short/long sentence, 2 repetitions).

\begin{tabular}{|c|c|c|c|c|c|c|}
\hline \multirow{3}{*}{$\begin{array}{l}\text { Type of target } \\
\text { sentence }\end{array}$} & \multicolumn{5}{|c|}{ Type of context sentence } & \multirow[b]{3}{*}{ Total } \\
\hline & \multicolumn{2}{|c|}{ Statement } & \multicolumn{2}{|c|}{ Y/N-question } & \multirow[b]{2}{*}{ None } & \\
\hline & 1st pos & 2nd pos & 1st pos & 2nd pos & & \\
\hline Statement & 10 & 10 & 10 & 10 & 10 & 50 \\
\hline Wh-question & 10 & 10 & 10 & 10 & 10 & 50 \\
\hline $\mathrm{Y} / \mathrm{N}$-question & 10 & 10 & 10 & 10 & 10 & 50 \\
\hline Declarative question & 10 & 10 & 10 & 10 & 10 & 50 \\
\hline Total & 40 & 40 & 40 & 40 & 10 & 200 \\
\hline
\end{tabular}

